\title{
Luminal-like HER2-negative stage IA breast cancer: a multicenter retrospective study on long-term outcome with propensity score analysis
}

\author{
Carmine De Angelis ${ }^{1}$, Massimo Di Maio ${ }^{2}$, Anna Crispo ${ }^{3}$, Mario Giuliano ${ }^{1,4}$, Francesco \\ Schettini $^{4}$, Marta Bonotto ${ }^{5}$, Lorenzo Gerratana ${ }^{6}$, Donatella Iacono ${ }^{5}$, Marika \\ Cinausero 6 , Ferdinando Riccardi7, Giuseppe Ciancia ${ }^{8}$, Michelino De Laurentiis ${ }^{9}$, \\ Fabio Puglisi6,10, Sabino De Placido ${ }^{4}$ and Grazia Arpino 4 \\ ${ }^{1}$ Lester and Sue Smith Breast Center, Baylor College of Medicine, Houston, Texas 77030, USA \\ ${ }^{2}$ Oncology Department, University of Turin, 10043 Orbassano, Italy \\ ${ }^{3}$ Epidemiology Department, 'Fondazione G. Pascale' Istituto Nazionale Tumori, 80131 Naples, Italy \\ ${ }^{4}$ Clinical Medicine and Surgery Department, University of Naples Federico II, 80131 Naples, Italy \\ ${ }^{5}$ Department of Medical and Biological Sciences, University of Udine, 33100 Udine, Italy \\ ${ }^{6}$ Department of Medicine (DAME), University of Udine, 33100 Udine, Italy \\ ${ }^{7}$ Medical Oncology Unit, Azienda Ospedaliera di Rilievo Nazionale A. Cardarelli, 80131 Naples, Italy \\ ${ }^{8}$ Advanced Biomedical Sciences Department, University of Naples Federico II, 80131 Naples, Italy \\ ${ }^{9}$ Breast Unit, 'Fondazione G. Pascale' Istituto Nazionale Tumori, 80131 Naples, Italy \\ ${ }^{10}$ Department of Clinical Oncology, CRO Aviano National Cancer Institute, 33081 Aviano, Italy \\ Correspondence to: Grazia Arpino, email: grazia.arpino@unina.it \\ Keywords: breast cancer; luminal-like; chemotherapy; hormone therapy; propensity score \\ Received: July 22, $2017 \quad$ Accepted: October 28, $2017 \quad$ Published: November 24, 2017 \\ Copyright: De Angelis et al. This is an open-access article distributed under the terms of the Creative Commons Attribution License \\ 3.0 (CC BY 3.0), which permits unrestricted use, distribution, and reproduction in any medium, provided the original author and \\ source are credited.
}

\section{ABSTRACT}

The benefit of adding chemotherapy (CT) to adjuvant hormone therapy (HT) in stage IA luminal-like HER2-negative breast cancer (BC) is unclear. We retrospectively evaluated predictive factors and clinical outcome of 1,222 patients from 4 oncologic centers. Three hundred and eighty patients received CT and HT (CT-cohort) and 842 received HT alone (HT-cohort). Disease-free survival (DFS) and overall survival (OS) were evaluated with univariate and multivariate analyses. We also applied the propensity score methodology. Compared with the HT-cohort, patients in the CT-cohort were more likely to be younger, have larger tumors of a higher histological grade that were Ki67-positive, and lower estrogen and progesterone receptor expression. At univariate analysis, a higher histological grade and Ki67 were significantly associated to a lower DFS. At multivariable analysis, only histological grade was predictive of DFS. The CT-cohort had a worse outcome than the HT-cohort in terms of DFS and OS, but differences disappeared when matched according to propensity score. In summary, patients with stage IA luminal-like BC had an excellent prognosis, however relapse and mortality were higher in the CT-cohort than in the HT-cohort. Longer use of adjuvant HT or other therapeutic strategies may be needed to improve outcome.

\section{INTRODUCTION}

Implementation of screening programs has increased the diagnosis of early stage breast cancers in westernized countries [1-6]. Among these cases, tumors measuring $\leq 2 \mathrm{~cm}$ without lymph node involvement (N0), classified as stage IA breast cancer [7], generally have a low rate of metastatic relapse and a favorable outcome [4, 8-13]. 
Adjuvant hormonal treatment (HT) is the main therapeutic option for patients with stage IA "luminal-like HER2negative" disease ("luminal-like breast cancer"), which is defined by the expression of hormone receptors (HR) and the absence of HER2 overexpression and/or amplification [14]. Clinical and tumoral features can help to characterize risk and select which patients may need CT in addition to HT. However, parameters such as tumor size and nodal status may not completely reflect the wide molecular heterogeneity seen among breast tumors even within the HR-positive subgroup [15]. Multigene prognostic tools are now beginning to guide treatment decision making. Of these, the Recurrence Score (RS) generated by the Oncotype DX® assay (Genomic Health, Redwood City, CA) gives a validated estimate of prognosis for patients with N0, estrogen receptor (ER)-positive disease if treated with tamoxifen alone $[16,17]$. However, genomic tests are not always available in clinical practice, and conventional tumoral and clinical parameters still play a critical role in disease management and are the most popular tools for risk stratification in this setting. Importantly, irrespective of the criteria chosen for risk stratification, the amount of benefit associated with the addition of CT to HT is unclear.

The aim of this study was to evaluate the clinical outcome of a large cohort of patients affected by luminallike stage IA breast cancer who received adjuvant HT with or without $\mathrm{CT}$, and the prognostic value of patient- and tumor-related markers.

\section{RESULTS}

\section{Population demographics and pathological features}

A total of 1,222 patients from 4 Italian Oncologic Centers with luminal-like stage IA breast cancer who underwent surgery between 1996 and 2012 were identified. Data on tumor size, histological grade, ER and PgR status and Ki67 were available for 97\% (1191), $96 \%(1,170), 99 \%(1,208), 98 \%(1,201)$ and $86 \%(1,049)$ of patients, respectively. The median age at the time of breast cancer diagnosis was 57 years (range:26-88 years; interquartile range, from 48 to 65 years) and 7\% (87) of cases were classified T1a, 32\% (381) T1b, and 61\% (723) T1c. All patients included in this study had received adjuvant systemic therapy. In detail, $69 \%$ of patients (842) were treated with HT alone, and 31\% (380) with CT followed by HT. The distribution of the adjuvant systemic treatments delivered in the different Oncologic Centers where patients were treated are shown in Supplementary Table 1. Seventy-eight percent (909) of tumors had a lowmoderate (G1-G2) histological grade, 65\% (687) had a low proliferation rate evaluated with a Ki67 threshold of $20 \%$, and 52\% (544) had a low ki67 evaluated using a threshold of $14 \%$. With respect to HR levels, $99 \%(1,208)$ of tumors were ER-positive, with a median ER positivity of $80 \%$ (range $0-100 \%)$, and 91\% (1,111) were PgR-positive, with a median PgR positivity of $70 \%$ (range $0-100 \%$ ). Among PgR-positive tumors, 81\% (965) had high levels of PgR $(\mathrm{PgR} \geq 20 \%)$.

The distribution of the demographic and pathologic characteristics of the CT vs HT cohort of patients is reported in Table 1. Age, tumor size, tumor grade, Ki67, ER and $\mathrm{PgR}$ expression differed significantly between the two cohorts. Patients in the CT cohort compared to those in the HT-cohort were more likely to be younger (median age 50 vs 61 years; $p<0.001$, respectively), and to have a larger tumor (T1c rates $81 \%$ vs. $52 \%$; $p<0.001$, respectively) that had a higher histological grade (G3 rates $47 \%$ vs $12 \%$; $<<0.001$, respectively), lower ER and PgR expression (ER positivity rate $96 \%$ vs $100 \%$; p $<0.001$; median levels of ER expression 70\% vs 90\%; $<<0.001$; median PgR levels 50\% vs 70\%; p $<0.001$, respectively) and a higher proliferation index for both $\mathrm{Ki} 67$ cut-offs (Ki67 > 20\% 56\% vs 25\%; p <0.001, and Ki67 >14\% 68\% vs $40 \%$; $<0.001$, respectively). Not surprisingly given the distribution of baseline characteristics, the rates of luminal A breast cancer were $23 \%$ vs $48 \%$ and the rates of luminal B breast cancer were $77 \%$ vs $52 \%$ in the CT-cohort vs the HT-cohort, respectively $(\mathrm{p}<0.001)$.

Information about chemotherapy regimen was available for $99 \%$ of patients in the CT cohort. In detail, $58 \%$ (219) of patients received anthracycline-containing only regimens, $16 \%$ (60) received regimens based on both anthracyclines and taxanes, $2 \%(8)$ received a taxanebased only regimen, and 23\% (89) received neither anthracycline- nor taxane-containing chemotherapy (Supplementary Table 2).

\section{Survival outcomes}

Overall, with a median follow-up of 8.3 years (range: 1 to 16.4 years) in the two cohorts, the outcome of patients was very favorable with DFS rates of $97.6 \%$ and $91.5 \%$ and OS rates of $99.4 \%$ and $98.3 \%$ at 5 and 10 years, respectively. At univariate analysis, only tumor grade and proliferation were significantly associated to DFS. In detail, DFS rates at 5 and 10 years were $94.4 \%$ and $84.9 \%$ vs $98.8 \%$ and $94.4 \%$ for patients with G3 vs G1-2 breast cancer (hazard ratio $=2.53,95 \%$ CI 1.42 to $4.51, \mathrm{p}=0.0017$, Figure $1 \mathrm{~A}$ ), and $95.4 \%$ and $86.8 \%$ vs $98.6 \%$ and $92.7 \%$ for patients with $\mathrm{Ki} 67 \geq 20 \%$ vs $\mathrm{Ki} 67$ $<20 \%$ (hazard ratio $=2.23,95 \%$ CI 1.24 to $4, \mathrm{p}=0.007$, Figure 1B), respectively. Overall survival was unrelated to the other study variables. The type of relapse/event (local relapses, distant relapses and death without relapse) and their distribution in the two cohorts of patients are reported in Supplementary Table 3. Survival outcomes by histological grade, $\mathrm{Ki} 67$ and $\mathrm{PgR}$ are reported in Supplementary Table 4.

Not surprisingly given the distribution of baseline prognostic factors, the CT-cohort had a statistically 
Table 1: Characteristics of tumors and patients at baseline

$\begin{array}{ll}\text { HT cohort } & \text { CT cohort }\end{array}$

$(N=842) \quad(N=380)$

\begin{tabular}{|c|c|c|c|}
\hline \multicolumn{4}{|l|}{ Age } \\
\hline Median (range) & $61(28-88)$ & $50(26-76)$ & $<0.001$ \\
\hline$<50$ yrs & $178(21 \%)$ & $179(47 \%)$ & \multirow{2}{*}{$<0.001$} \\
\hline$\geq 50$ yrs & $664(79 \%)$ & $201(53 \%)$ & \\
\hline \multicolumn{4}{|c|}{ Tumor size $(N=1,191)$} \\
\hline T1a & $81(10 \%)$ & $6(2 \%)$ & \multirow{3}{*}{$<0.001$} \\
\hline $\mathrm{T} 1 \mathrm{~b}$ & $317(38 \%)$ & $64(18 \%)$ & \\
\hline T1c & $428(52 \%)$ & $295(81 \%)$ & \\
\hline \multicolumn{4}{|l|}{ Grade $(N=1,170)$} \\
\hline G1-2 & $719(88 \%)$ & $190(53 \%)$ & \multirow{2}{*}{$<0.001$} \\
\hline G3 & $95(12 \%)$ & $166(47 \%)$ & \\
\hline \multicolumn{4}{|l|}{$\operatorname{Ki67}(N=1,049)$} \\
\hline$<20 \%$ & $553(75 \%)$ & $134(44 \%)$ & \multirow{2}{*}{$<0.001$} \\
\hline$\geq 20 \%$ & $188(25 \%)$ & $174(56 \%)$ & \\
\hline$\leq 14 \%$ & $444(60 \%)$ & $100(32 \%)$ & \multirow{2}{*}{$<0.001$} \\
\hline$>14 \%$ & $297(40 \%)$ & $208(68 \%)$ & \\
\hline \multicolumn{4}{|l|}{ ER } \\
\hline Positive $(\geq 1 \%)$ & $842(100 \%)$ & $366(96 \%)$ & $<0.001$ \\
\hline Median (range) & $90 \%(10-100 \%)$ & $70 \%(0-80 \%)$ & $<0.001$ \\
\hline \multicolumn{4}{|l|}{ PgR } \\
\hline Positive $(\geq 1 \%)$ & $770(92 \%)$ & $341(90 \%)$ & 0.24 \\
\hline $\operatorname{High}(\geq 20 \%)$ & $686(83 \%)$ & $279(75 \%)$ & 0.002 \\
\hline Median (range) & $70 \%(0-100 \%)$ & $50 \%(0-100 \%)$ & $<0.001$ \\
\hline \multicolumn{4}{|c|}{ Luminal $(N=1040)$} \\
\hline Luminal A & $350(48 \%)$ & $70(23 \%)$ & \multirow{2}{*}{$<0.001$} \\
\hline Luminal B & $384(52 \%)$ & $236(77 \%)$ & \\
\hline
\end{tabular}

Luminal A: ER+ (>1\%), PgR high ( $\geq 20 \%)$, HER 2-negative and Ki67 $\leq 14 \%$; Luminal B: ER+ $(>1 \%)$; PgR low $(<20 \%)$ and/or $\mathrm{Ki} 67>14 \%$.

significant worse outcome compared to the HT-cohort with regard of DFS (hazard ratio $=2.17,95 \%$ CI 1.26 to $3.75, \mathrm{p}=0.005$; Figure $2 \mathrm{~A}$ ) and $\mathrm{OS}$ (hazard ratio $=4.32$, $95 \%$ CI 1.13 to $16.5, p=0.032$; Figure $2 B$ ) at 5 years and 10 years. Disease-free survival rates at 5 and 10 years were $95.6 \%$ (95\% CI, 93.6\%-97.8\%) and 87.8\% (95\% CI, $83.0 \%-92.8 \%$ ) in the CT-cohort vs $98.5 \%$ (95\% CI, $97.7 \%$ to $99.4 \%)$ and $94.1 \%(95 \% \mathrm{CI}, 91.2 \%-97.2 \%)$ in the HTcohort, respectively (Table 2). Overall survival rates at 5 and 10 years were $98.9 \%$ (95\% CI, 97.8\%-100\%) and $96.9 \%(95 \% \mathrm{CI}, 94.3 \%-99.6 \%)$ in the CT-cohort and
99.7\% (95\% CI, 99.3\%-100\%) and 99.4\% (95\% CI, 98.5\%-100\%) in the HT-cohort, respectively (Table 3).

To evaluate in greater detail the impact of adjuvant treatment choice on clinical outcomes in a more homogeneous population, we analyzed survival outcome in a subgroup of 408 patients matched by propensity score (204 patients from the CT-cohort and 204 patients from the HT-cohort). The baseline characteristics of patients with luminal-like stage IA breast cancer matched by propensity score are reported in Supplementary Table 5. The items matched were patient's age, tumor size 
category, histological grade, $\mathrm{PgR}$ expression, using a cut off of 20\%, and Ki67 index, as a continuous variable. When variables were well balanced, neither DFS nor OS differed significantly between the two study cohorts (Figure $3 \mathrm{~A}$ and 3B, respectively). We also explored the interaction between $\mathrm{CT}$ efficacy and Ki67 levels, and found it was not significant (data not shown); however, the number of events was too low to achieve sufficient statistical power.

\section{Multivariate analyses}

In a multivariable analysis, stratified by Oncologic Center, that included patient's age $(<50$ years vs $\geq 50$ years), tumor size (T1a vs T1b vs T1c), histological grade (G1-G2 vs G3), tumor proliferation (Ki67 as a continuous variable), PgR levels $(<20 \%$ vs $\geq 20 \%)$ and chemotherapy treatment (yes vs no), only histological grade had an independent prognostic value in predicting DFS (hazard ratio for G3 vs. G1-2 $=2.41,95 \%$ CI 1.10 to 5.28, $\mathrm{p}=0.028$; Table 4).

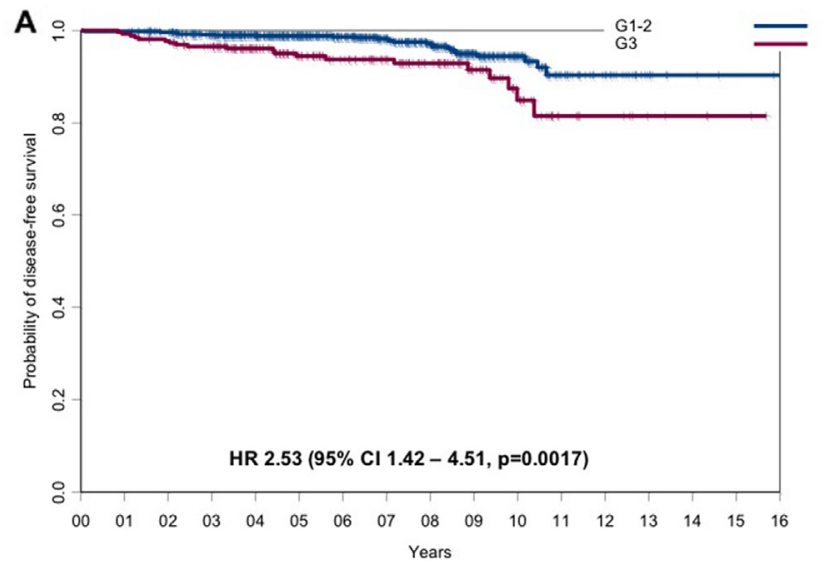

\section{DISCUSSION}

Overall, our patients with luminal-like stage IA breast cancer had an excellent prognosis with survival rates at 5 and 10 years of $99 \%$ and $98 \%$, respectively. Risk stratification, in our patients, was based on clinical and tumor parameters. As expected, given that the decision of proposing adjuvant CT was left to the physician, patients receiving this therapy were more likely to have worse prognostic characteristics (larger tumors with a higher proliferation index, higher tumor grade and lower ER and PgR expression levels) than patients receiving HT only. Among the clinical and immunohistochemical (IHC) parameters analyzed, only tumor grade was significantly related to DFS in our patients. Interestingly, despite the use of adjuvant CT, patients in the CT cohort still relapsed and their death rate was higher than that of the HT cohort. Moreover, when all the clinical and tumor features were matched by the propensity score, the addition of CT did not significantly improve either DFS or OS compared to HT alone.

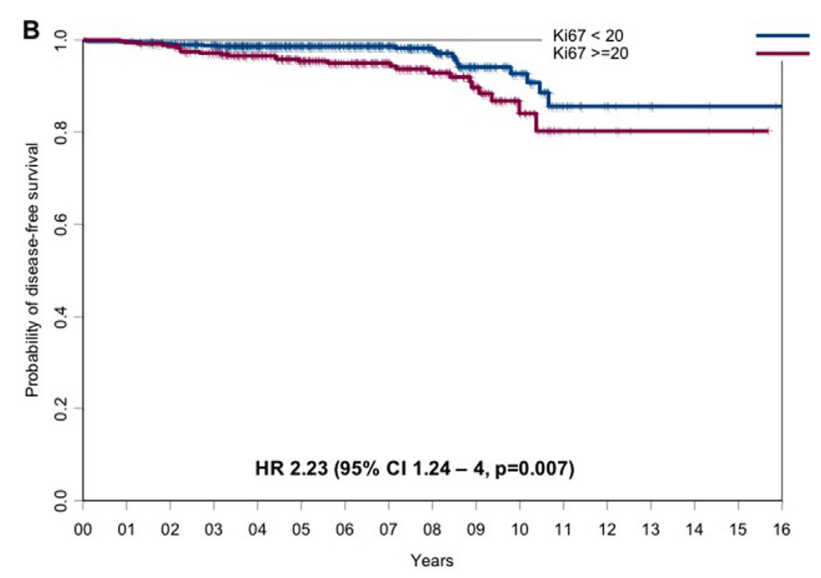

Figure 1: Disease-free survival according to the main prognostic factors. (A) DFS for G1-2 vs G3 tumors and (B) DFS for tumors with $\mathrm{Ki} 67<20 \%$ vs tumors with $\mathrm{Ki} 67 \geq 20 \%$.
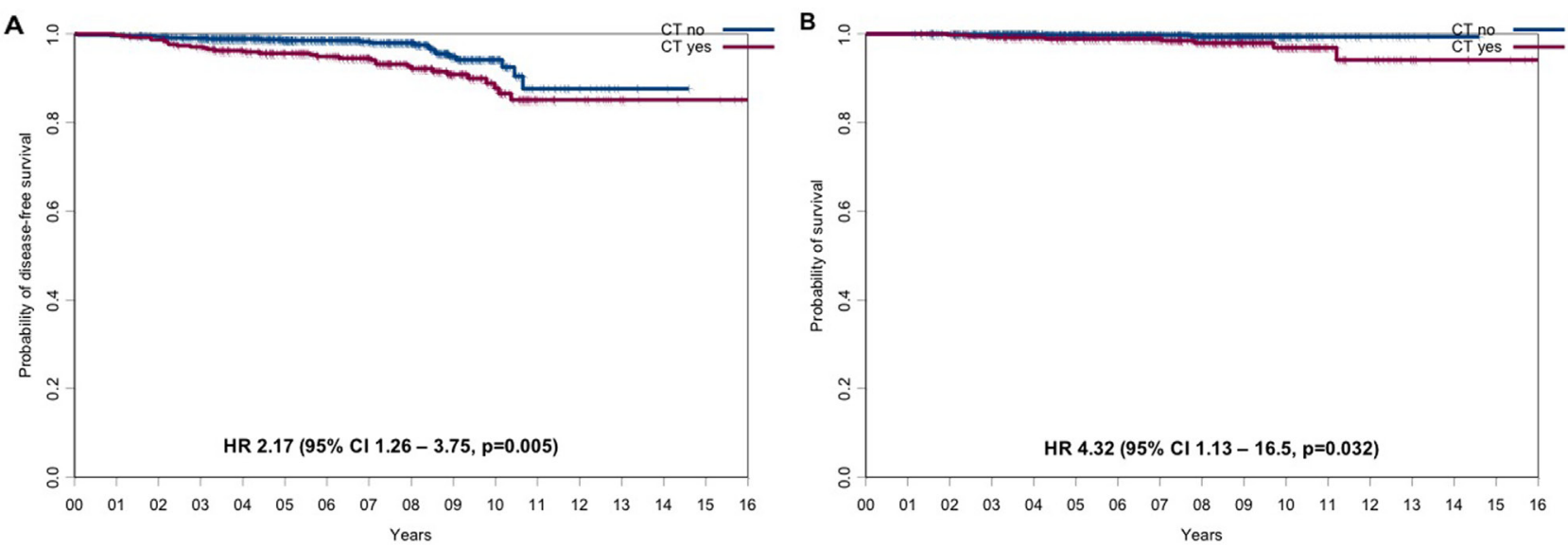

Figure 2: DFS and OS for the CT-cohort vs the HT-cohort. (A) DFS and (B) OS for the CT-cohort vs the HT-cohort. 
Table 2: DFS rates for HT-cohort vs CT-cohort

\begin{tabular}{|c|c|c|c|c|c|}
\hline Cohort & N. of patients & N. of events & $\begin{array}{c}\text { DFS rates at } 5 \\
\text { years }(95 \% \text { CIs) }\end{array}$ & $\begin{array}{l}\text { DFS rates at } 10 \\
\text { years }(95 \% \mathrm{CI})\end{array}$ & $\begin{array}{c}\text { Hazard Ratio } \\
\text { (95\% CI) } \\
\text { CT vs HT }\end{array}$ \\
\hline HT-cohort & 842 & 23 & $\begin{array}{c}98.5 \% \\
(97.7 \%-99.4 \%)\end{array}$ & $\begin{array}{c}94.1 \% \\
(91.2 \%-97.2 \%)\end{array}$ & $2.17(1.26-3.75)$ \\
\hline CT-cohort & 380 & 32 & $\begin{array}{c}95.6 \% \\
(93.6 \%-97.8 \%)\end{array}$ & $\begin{array}{c}87.8 \% \\
(83 \%-92.8 \%)\end{array}$ & $\mathrm{p}=0.005^{*}$ \\
\hline Whole population & 1,222 & 55 & $\begin{array}{c}97.6 \% \\
(96.6 \%-98.6 \%)\end{array}$ & $\begin{array}{c}91.5 \% \\
(88.6 \%-94.4 \%)\end{array}$ & \\
\hline
\end{tabular}

${ }^{*}$ Univariate log rank test.

Table 3: OS rates for HT vs CT-cohort

\begin{tabular}{|c|c|c|c|c|c|}
\hline Cohort & N. of patients & N. of events & $\begin{array}{c}\text { OS rates at } 5 \\
\text { years }(95 \% \mathrm{CI})\end{array}$ & $\begin{array}{c}\text { OS rates at } 10 \\
\text { years }(95 \% \mathrm{CI})\end{array}$ & $\begin{array}{c}\text { Hazard Ratio } \\
\text { (95\% CI) } \\
\text { CT vs HT }\end{array}$ \\
\hline HT-cohort & 842 & 3 & $\begin{array}{c}99.7 \% \\
(99.3 \%-100 \%)\end{array}$ & $\begin{array}{c}99.4 \% \\
(98.5 \%-100 \%)\end{array}$ & $\begin{array}{c}4.32 \\
(13-165)\end{array}$ \\
\hline CT-cohort & 380 & 9 & $\begin{array}{c}98.9 \% \\
(97.8 \%-100 \%)\end{array}$ & $\begin{array}{c}96.9 \% \\
(94.3 \%-99.6 \%)\end{array}$ & $\mathrm{p}=0.032^{*}$ \\
\hline Whole population & 1,222 & 12 & $\begin{array}{c}99.4 \% \\
(99.0 \%-99.8 \%)\end{array}$ & $\begin{array}{c}98.3 \% \\
(96.9 \%-99.7 \%)\end{array}$ & \\
\hline
\end{tabular}

*univariate log rank test.
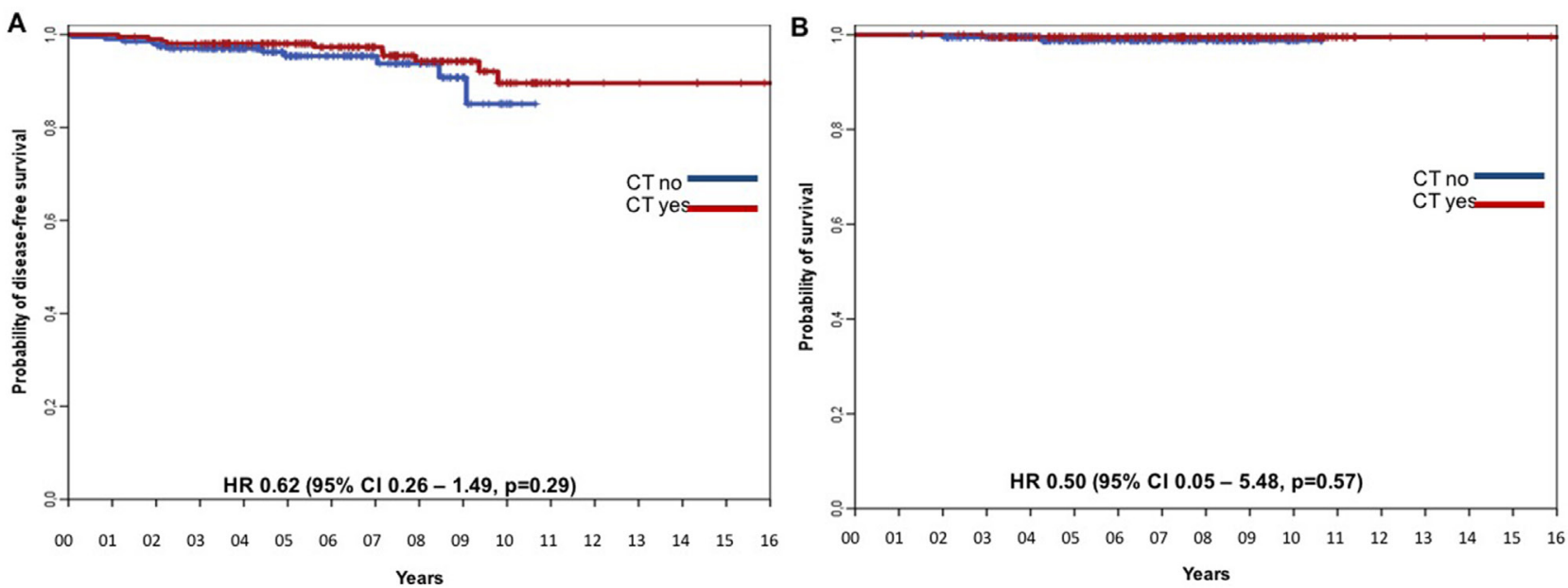

Figure 3: DFS for the CT-cohort vs the HT-cohort matched by propensity score. (A) DFS and (B) OS for the CT-cohort vs HT-cohort matched by propensity score with Ki67 as continuous variable. 
Table 4: Multivariate analyses with Cox regression model for DFS, stratified by oncologic center

\begin{tabular}{lcccc}
\hline & Covariates & Hazard Ratios & 95\% CI & P value \\
\hline Chemotherapy & Yes vs No & 0.66 & $0.28-1.57$ & 0.35 \\
Age & $\geq 50$ vs. $<50$ & 0.90 & $0.41-1.96$ & 0.79 \\
T category & T1c vs T1b vs T1a & 2.00 & $0.97-4.14$ & 0.06 \\
Grading & G3 vs G1-2 & 2.50 & $1.14-5.48$ & $\mathbf{0 . 0 2 2}$ \\
Ki67 & continuous variable & 1.01 & $0.98-1.04$ & 0.58 \\
ER & continuous variable & 1.00 & $0.98-1.02$ & 0.87 \\
PgR & continuous variable & 1.00 & $0.99-1.01$ & 0.95 \\
\hline
\end{tabular}

In the present study, patients' age, tumor size, grade and proliferation, and median levels of ER and PgR expression played a critical role in disease management and guided physicians and patients in therapeutic decisionmaking. Interestingly, however, we found that among all the clinical parameters and IHC-defined molecular biomarkers studied, only tumor grade correlated with DFS. Tumor differentiation is a well-established prognostic factor for breast cancer, and the grade score may affect the recommendation for CT in ER-positive tumors [18]. Our data and those of others [17], support the role of tumor grade in identifying, among patients with stage IA luminal breast cancer, women who may be at a higher risk of relapse, and may eventually need adjuvant CT.

The low rate of distant recurrence observed in the patients of the HT-cohort is consistent with previous reports $[11,12,19-21]$ and is also in line with a risk of relapse of approximately $1 \%$ at 5 years reported by Sparano et al. in a similar patient population at a low risk based on clinicopathological features and receiving HT alone [17].

Not surprisingly, our patients in the CT-cohort had worse clinical and tumor characteristics and worse relapse and survival rates at 5 and 10 years compared to patients in the HT cohort. Of course, our results may reflect the increased baseline risk of patients in the $\mathrm{CT}$ cohort. However, the net benefit of adding CT to HT could not be evaluated in our study due to the lack of randomization and the retrospective nature of the analysis. In any event, when the patients' baseline and tumor characteristics were matched by the propensity score, the addition of CT to HT did not further improve either DFS or OS. A recent metaanalysis [22] demonstrated that new generation taxaneplus-anthracycline chemotherapy regimens reduced the 10 -year risk of death from breast cancer by about a third. However, as relatively few patients in the trials included in the meta-analysis had small, well-differentiated luminal A-like tumors, no definitive conclusions can be drawn about the effects of CT on such low-risk tumors.

The predominant use of older taxane-free chemotherapy regimens in the present study (only
$16 \%$ of patients had received taxane and anthracycline regimens) and the relative endocrine resistance of these largely luminal B tumors may also have influenced patients' outcome. Furthermore, data from recent neoadjuvant studies show that patients with ERpositive tumors are less likely to achieve a complete response to chemotherapy [23-26] which suggests that ER positivity can also affect the proportional risk reduction seen with adjuvant chemotherapy. New generation taxane-plus-anthracycline chemotherapy regimens, longer duration of endocrine therapies, new molecules able to more effectively block the ER pathways or other critical cell checkpoints such as cyclin inhibitors may be required to further improve survival in this cohort of patients. In this context, it is feasible that genomic tests $[21,27,28]$ will help to better stratify patients according to different risk of recurrence categories [29] and define the best adjuvant strategy.

Our study has several limitations. It is a multicenter retrospective evaluation, treatment allocation was not randomly assigned and pathology was not centralized. However, the homogeneity of the patient population, propensity score matching and multivariate analysis may counteract these limitations.

In conclusion, we confirm the overall excellent prognosis of stage I luminal breast cancer. We did not identify any molecular or clinical parameters other than tumor grade able to predict patient outcome. Notably, our study shows that low-risk ER-positive disease may be treated with HT alone and, because further risk reduction from adding $\mathrm{CT}$, if any, will not be large in absolute terms, this therapeutic strategy should be weighed against its toxicity. Gene expression profiling may provide additional information to better select these patients in daily clinical practice. More studies are needed to improve outcome in patients with stage I luminal breast cancer who require CT because of a highrisk score at genetic testing or a worse IHC molecular profile, because chemotherapy and 5 years HT may not be sufficient. 


\section{MATERIALS AND METHODS}

\section{Study population}

We retrospectively collected the clinical and pathological data of early breast cancer patients who underwent surgery between 1996 and 2012 in four Italian oncologic centers (University of Naples "Federico II", National Cancer Institute "G. Pascale", Naples, AORN "A. Cardarelli" Hospital, Naples, and the "Santa Maria della Misericordia" University Hospital, Udine).

Pathologic data on tumor size (T), nodal status (N), histological grade $(\mathrm{G})$, tumor proliferation measured by Ki67 labeling, estrogen receptor (ER), progesterone receptor (PgR) and HER2/neu status of each patient were retrieved. Breast tumors were staged according to the $7^{\text {th }}$ edition of the American Joint Committee on Cancer Staging (AJCC) Manual [7]. The histological grade was defined using the modified Bloom-RichardsonElston grading system [30]. The Ki67 percentage score was assessed using the MIB1 monoclonal antibody $[31,32]$. Two thresholds for Ki67 positivity $(14 \%$ and $20 \%$ ) were considered. HR expression was considered positive in case of ER and/or PgR immunostaining greater than $1 \%$ of invasive cells. ER and PgR were analyzed as described elsewhere [33]. PgR expression was considered high at a threshold of $20 \%$, according to the St. Gallen Consensus [14]. HER2 receptor status was evaluated by IHC and expression level $3+$ staining (DAKO Herceptest) was considered positive. In case of HER2 2+ staining, fluorescence in situ hybridization, chromogenic in situ hybridization, or silver in situ hybridization was performed to identify HER 2 gene amplification. All tumors were classified as luminal-like breast cancers, with luminal-like A and B distinguished according to the St. Gallen Consensus [14]. In detail, tumors were classified as luminal A-like if ER positive $(>1 \%)$, PgR high $(\geq 20 \%)$, HER2 negative and Ki67 low $(\leq 14 \%)$ or luminal B-like if ER positive $(>1 \%)$ and $\mathrm{PgR}$ low $(<20 \%)$ and/or Ki67 high ( $>14 \%)$. Patients with a diagnosis of breast carcinoma in situ (Tis), or of invasive carcinoma with no invasive lesion measuring more than $1 \mathrm{~mm}$ (T1mic), or a follow-up shorter than 1 year were excluded from the analysis. Overall, 1,222 patients with luminal-like stage IA breast cancer were retrospectively identified: 380 patients received CT and HT (CT-cohort) and 842 HT only (HT-cohort) as adjuvant therapy. All patients received postoperative local irradiation if indicated according to current guidelines and patient comorbidities.

This study was approved by the Ethic Committees of each participant center (IRB protocol number for Coordinating Center: 178/15). Due to the retrospective nature of the study, written informed consent was waived, according to Italian Law.

\section{Statistical analyses}

Patients were divided into two cohorts according to the adjuvant systemic treatment administered: HT alone (HT-cohort) and CT followed by HT (CT-cohort). The $\chi 2$ test was used to assess differences between the groups in the distribution of categorical prognostic variables [34]. Disease-free survival was defined as the time from surgery to the date of the first event, including local or distant recurrence or death, whichever occurred first. For survivors, DFS was censored at the date of the last available follow-up. Overall survival was defined as the time from surgery until the date of death (from any cause) with censoring at the date of last available follow-up. The DFS and OS distributions were estimated using the Kaplan-Meier method [35]. The log-rank test was used to assess the difference in survival distribution between the groups [36]. Multivariate Cox proportional hazard regression analysis [37] was used to assess the independent prognostic significance of the various clinical and pathological characteristics on DFS or OS. To reduce biases related to the non-random assignment of the compared treatment strategies (CT cohort vs HT cohort), we applied the propensity score methodology [38-40]. With this method, the relationship between therapy and outcome is adjusted for the likelihood that a patient has of receiving that treatment, given her baseline characteristics. In detail, the propensity score (chance of receiving chemotherapy) was estimated by a logistic regression model that included, as dependent variable, the receipt of chemotherapy and, as covariates, factors that are likely to influence the decision whether or not to administer chemotherapy (age, tumor category, grading, PgR expression category and Ki67 value). Only subjects with overlapping values of the propensity score were included in the matched groups, with a 1:1 matching between the two study cohorts, allowing a 0.2 caliper (i.e. the maximum tolerated difference in the propensity score between matched subjects). After matching, patients of the 2 groups had a similar distribution of propensity scores, and consequently the 2 matched groups are similar in terms of age, T, grading, PgR and Ki67, whereas these factors differed greatly between the two unmatched groups.

Statistical analyses were performed with S-PLUS 6.0 Professional (release 1; Insightful Corporation, Seattle, WA, USA) and IBM SPSS Statistics (release 24.0.0.0). Propensity score analysis was performed using Propensity Score Matching for SPSS, Version 3.0.4 (Thoemmes, F. 2012. Propensity score matching in SPSS. arXiv:1201.6385).

\section{Abbreviations}

BC: breast cancer; CI: confidence interval; CT: chemotherapy; DFS: disease-free survival; ER: estrogen receptor; G: tumor grading; HR: hormone receptors; HT: 
hormone therapy; N: lymph nodal involvement; OS: overall survival; PGR: progesterone receptor; T: tumor size.

\section{Author contributions}

All authors conceived the study. FS, MB, LG, DI and MC collected the data, MDM performed the statistical analyses. FS, CDA, GA and MDM wrote the paper. All authors revised and accepted the final version of the manuscript.

\section{ACKNOWLEDGMENTS}

We gratefully thank Jean Ann Gilder (Scientific Communication srl., Naples, Italy) for editing the article.

\section{CONFLICTS OF INTEREST}

The authors have declared no conflicts of interest.

\section{FUNDING}

None declared.

\section{REFERENCES}

1. Buiatti E, Barchielli A, Bartolacci S, Federico M, De Lisi V, Bucchi L, Ferretti S, Paci E, Segnan N, Tumino R; SCREENREG Working Group. The impact of organised screening programmes on the stage-specific incidence of breast cancer in some Italian areas. Eur J Cancer. 2003; 39:1776-1782.

2. Iqbal J, Ginsburg O, Rochon PA, Sun P, Narod SA. Differences in Breast Cancer Stage at Diagnosis and Cancer-Specific Survival by Race and Ethnicity in the United States. JAMA. 2015; 313:165-173.

3. Siegel R, Ma J, Zou Z, Jemal A. Cancer statistics. CA Cancer J Clin. 2014; 64:9-29.

4. Howlader N, Noone AM, Krapcho M, Miller D, Bishop K, Kosary CL, Yu M, Ruhl J, Tatalovich Z, Mariotto A, Lewis DR, Chen HS, Feuer EJ, et al. (eds). SEER Cancer Statistics Review, 1975-2014, National Cancer Institute. Bethesda, MD, https:// seer.cancer.gov/csr/1975_2014/, based on November 2016 SEER data submission, posted to the SEER web site, April 2017.

5. Fracheboud J, Otto SJ, van Dijck JA, Broeders MJ, Verbeek AL, de Koning HJ; National Evaluation Team for Breast cancer screening (NETB). Decreased rates of advanced breast cancer due to mammography screening in The Netherlands. Br J Cancer. 2004; 91:861-867.

6. Luke C, Nguyen AM, Priest K, Roder D. Female breast cancers are getting smaller, but sociodemographic differences remain. Aust N Z J Public Health. 2004; 28:312-316.

7. Edge S, Byrd DR, Compton CC, Fritz AG, Greene FL, Trotti A, editors. (2010) AJCC Cancer Staging Manual (7th Edition). Springer-Verlag: New York.
8. Bland KI, Menck HR, Scott-Conner CE, Morrow M, Winchester DJ, Winchester DP. The National Cancer Data Base 10-year survey of breast carcinoma treatment at hospitals in the United States. Cancer. 1998; 83:1262-1273.

9. Amar S, McCullough AE, Tan W, Geiger XJ, Boughey JC, McNeil RB, Coppola KE, McLaughlin SA, Palmieri FM, Perez ED. Prognosis and outcome of small $(\leq 1 \mathrm{~cm})$, nodenegative breast cancer on the basis of hormonal and HER-2 status. Oncologist. 2010; 15:1043-1049.

10. Garassino I, Gullo G, Orefice S Tondulli L, Masci G, Salvini P, Eboli M, Di Tommaso L, Giordano L, Alloisio M, Roncalli M, Santoro A. Outcome of T1N0M0 breast cancer in relation to St. Gallen risk assignment criteria for adjuvant therapy. Breast. 2009; 18:263-266.

11. Gamucci T, Vaccaro A, Ciancola F, Pizzuti L, Sperduti I, Moscetti L, Longo F, Fabbri MA, Giampaolo MA, Mentuccia L, Di Lauro L, Vici P. Recurrence risk in small, node-negative, early breast cancer: a multicenter retrospective analysis. J Cancer Res Clin Oncol. 2013; 139:853-860.

12. Hanrahan EO, Gonzalez-Angulo AM, Giordano SH, Rouzier R, Broglio KR, Hortobagyi GN, Valero V. Overall survival and cause-specific mortality of patients with stage T1a, bN0M0 breast carcinoma. J Clin Oncol. 2007; 25:4952-4960.

13. Cancello G, Maisonneuve P, Rotmensz N, Viale G, Mastropasqua MG, Pruneri G, Montagna E, Dellapasqua S, Iorfida M, Cardillo A, Veronesi P, Luini A, Intra M, et al. Prognosis in women with small (T1mic, T1a, T1b) nodenegative operable breast cancer by immunohistochemically selected subtypes. Breast Cancer Res Treat. 2011; 127:713-720.

14. Coates AS, Winer EP, Goldhirsch A, Gelber RD, Gnant M, Piccart-Gebhart M, Thürlimann B, Senn HJ; Panel Members. Tailoring therapies-improving the management of early breast cancer: St Gallen International Expert Consensus on the Primary Therapy of Early Breast Cancer 2015. Ann Oncol. 2015; 26:1533-46.

15. Sotiriou C, Pusztai LN. Gene expression signatures in breast cancer. N Engl J Med. 2009; 360:790-800

16. Paik S, Tang G, Shak S, Kim C, Baker J, Kim W, Cronin M, Baehner FL, Watson D, Bryant J, Costantino JP, Geyer CE Jr, Wickerham DL, et al. Gene expression and benefit of chemotherapy in women with node-negative, estrogen receptor-positive breast cancer. J Clin Oncol. 2006; 24:3726-3734.

17. Sparano JA, Gray RJ, Makower DF, Pritchard KI, Albain KS, Hayes DF, Geyer CE Jr, Dees EC, Perez EA, Olson JA Jr, Zujewski J, Lively T, Badve SS, et al. Prospective validation of a 21-gene Expression assay in breast cancer. N Engl J Med. 2015; 373:2005-2014.

18. Curigliano G, Burstein HJ, P Winer E, Gnant M, Dubsky P, Loibl S, Colleoni M, Regan MM, Piccart-Gebhart M, Senn HJ, Thürlimann B, André F, Baselga J, et al; St. Gallen International Expert Consensus on the Primary Therapy 
of Early Breast Cancer 2017. De-escalating and escalating treatments for early-stage breast cancer: the St. Gallen International Expert Consensus Conference on the Primary Therapy of Early Breast Cancer 2017. Ann Oncol. 2017; 28:1700-1712.

19. Sparano JA, Paik S. Development of the 21-gene assay and its application in clinical practice and clinical trials. J Clin Oncol. 2008; 26:721-728.

20. Paik S, Shak S, Tang G, Kim C, Baker J, Cronin M, Baehner FL, Walker MG, Watson D, Park T, Hiller W, Fisher ER, Wickerham DL, et al. A multigene assay to predict recurrence of tamoxifen-treated, node-negative breast cancer. N Engl J Med. 2004; 351:2817-2826.

21. Sparano JA, Zhao F, Martino S, Ligibel JA, Perez EA, Saphner T, Wolff AC, Sledge GW Jr, Wood WC, Davidson NE. Long-term follow-up of the E1199 phase III trial evaluating the role of taxane and schedule in operable breast cancer. J Clin Oncol. 2015; 33:2353-2360.

22. Goss PE, Ingle JN, Martino S, Robert NJ, Muss HB, Piccart MJ, Castiglione M, Tu D, Shepherd LE, Pritchard KI, Livingston RB, Davidson NE, Norton L, et al. A randomized trial of letrozole in postmenopausal women after five years of tamoxifen therapy for early-stage breast cancer. N Engl J Med. 2003; 349:1793-1802.

23. Davies C, Pan H, Godwin J, Gray R, Arriagada R, Raina V, Abraham M, Medeiros Alencar VH, Badran A, Bonfill X, Bradbury J, Clarke M, Collins R, et al, for the Adjuvant Tamoxifen: Longer Against Shorter (ATLAS) Collaborative Group. Long-term effects of continuing adjuvant tamoxifen to 10 years versus stopping at 5 years after diagnosis of oestrogen receptor-positive breast cancer: ATLAS, a randomised trial. Lancet. 2013; 381:805-816.

24. Straver ME, Glas AM, Hannemann J. Wesseling J, van de Vijver MJ, Rutgers EJ, Vrancken Peeters MJ, van Tinteren H, Van't Veer LJ, Rodenhuis S. The 70-gene signature as a response predictor for neoadjuvant chemotherapy in breast cancer. Breast Cancer Res Treat. 2010; 119:551-8.

25. Montagna E, Bagnardi V, Rotmensz N, Viale G, Pruneri G, Veronesi P, Cancello G, Balduzzi A, Dellapasqua S, Cardillo A, Luini A, Zurrida S, Gentilini O, et al. Pathological complete response after preoperative systemic therapy and outcome: relevance of clinical and biologic baseline features. Breast Cancer Res Treat. 2010; 124:689-699.

26. International Breast Cancer Study Group (IBCSG). Endocrine responsiveness and tailoring adjuvant therapy for postmenopausal lymph node-negative breast cancer: a randomized trial. J Natl Cancer Inst. 2012; 94:1054-1065.

27. Drukker CA, van Tinteren H, Schmidt MK, Rutgers EJ, Bernards R, van de Vijver MJ, Van't Veer LJ. Long-term impact of the 70-gene signature on breast cancer outcome. Breast Cancer Res Treat. 2014; 143:587-592.
28. Nielsen T, Wallden B, Schaper C, Ferree S, Liu S, Gao D, Barry G, Dowidar N, Maysuria M, Storhoff J. Analytical validation of the PAM50-based Prosigna Breast Cancer Prognostic Gene Signature Assay and nCounter Analysis System using formalin-fixed paraffin-embedded breast tumor specimens. BMC Cancer. 2014; 14:177.

29. Arpino G, Generali D, Sapino A, Del Mastro L, Frassoldati A, de Laurentis M, Paolo P, Mustacchi G, Cazzaniga M, De Placido S, Conte P, Cappelletti M, Zanoni V, et al. Gene expression profiling in breast cancer: A clinical perspective. The Breast. 2013; 22:109-120.

30. Elston CW, Ellis IO. Pathologic prognostic factors in breast cancer. I. The value of histological grades in breast cancer. Experience from a large study with long-term follow-up. Histopathology. 1991; 19:403-410.

31. Klintman E, Bendhal PO, Grabau D, Lövgren K, Malmström P, Fernö M; South Sweden Breast Cancer Group. The prognostic value of $\mathrm{Ki} 67$ is dependent on estrogen receptor status and histological grade in premenopausal patients with node-negative breast cancer. Modern Pathology. 2010; 23:251-259.

32. Malmstrom P, Bendahl PO, Boiesen P, Brünner N, Idvall I, Fernö M; South Sweden Breast Cancer Group. S-phase fraction and urokinase plasminogen activator are better markers for distant recurrences than Nottingham Prognostic Index and histologic grade in a prospective study of premenopausal lymph node-negative breast cancer. J Clin Oncol. 2001; 19:2010-2019.

33. Balaton AJ, Baviera EE, Galet B, Vaury P, Vuong PN. Immunohistochemical evaluation of estrogen and progesterone receptors on paraffin sections of breast carcinomas. Practical thoughts based on the study of 368 cases. Arch Anat Cytol Pathol. 1995; 43:93-100.

34. Ludbrook J. Analysis of $2 \times 2$ tables of frequencies: matching test to experimental design. Int J Epidemiol. 2008; 37:1430-1435.

35. Kaplan EL, Meier P. Nonparametric estimation from incomplete observations. J Amer Statist Assn. 1958; 53:457-481.

36. Peto R, Peto J. Asymptotically Efficient Rank Invariant Test Procedures. J Royal Stat Soc A. 1972; 135:185-207.

37. Armitage P, Berry G, Matthews JNS. Statistical Methods in Medical Research (4th Edition). Blackwell Science: Oxford. 2001.

38. Rosenbaum PR, Rubin DB. The central role of the propensity score in observational studies for causal effects. Biometrika. 1983; 70:41-55.

39. Rosenbaum PR. Optimal matching for observational studies. J Amer Statist Assn. 1989; 84:1024-1032.

40. Rubin DB. Estimating causal effects from large data sets using propensity scores. Ann Int Med. 1997; 127:757-763. 